\title{
The Developmental Tasks and The Binge Drinking
}

\author{
Lidia Susana Mendes Moutinho* \\ Department of Nursing, Ribeiro Sanchez High School, Portugal \\ *Corresponding author: Lidia Susana Mendes Moutinho, Department of Nursing, Ribeiro Sanchez High School, Portugal \\ To Cite This Article: Lidia Susana Mendes Moutinho. The Developmental Tasks and The Binge Drinking. Am J Biomed Sci \& Res. 2019 - 3(1). \\ AJBSR.MS.ID.000638. DOI: 10.34297/AJBSR.2019.03.000638
}

Received: May 11, 2019 | Published: May 23, 2019

Keywords: Binge drinking; Young people; Developmental tasks

\section{Introduction}

In the last decade alcohol consumption in Europe has stabilized, nevertheless a high rate of Binge Drinking (BD) still occurs which means a consumption over $60 \mathrm{gr}$ or more of pure alcohol in one occasion at least once in the last month. This type of consumption is the most appreciated by the young people. The age of BD is most prevalent between 20-24 years [1].

The age range in which this type of consumption has more followers is also the age that the integration of many developmental tasks is expected. According to Theory of Development of Erickson the people between the ages of 20 and 35 are in the stage designated as young adults. This stage of development suggests significant changes and an increase of responsibility which is a long-term commitment to sharing, companionship, monogamous relationships and a desire to start a family. These features symbolise dedication, expression and development of the individual's identity. Other author, Arnett [2] proposes an identification of an "emerging adulthood, between 20 to 30 years, which are the life span between the adolescence, and full-fledged adulthood which encompasses late adolescence and early adulthood. This stage is considered by being the age of explorations, of identity in love and work relationships, by the instability marked by the change in employment and educational status, to focus on the self and putting aside family values. In this stage the young people have the possibility to explore different life options, experience various roles and develop coping strategies to deal with negative emotional states as well as strategies for self-control and emotional regulation [3].

The different studies that have addressed the phenomenon of BD show the use of alcoholic beverages as a strategy to deal with stressors [4,5]. Reduced emotional control, difficulty in making decisions and a reduced number of strategies to deal with different emotional states are referred to as predictors of this type of consumption [3].
The ingestion of alcoholic drinks performed in an abusive way by the young people has the objective of disinhibition, euphoria and later a sensation of relaxation. It is also known that positive expectations regarding alcohol consumption are associated with loss of control and, consequently, socially inadequate behaviors such as alcohol-induced behavior, sexual risk behavior and consumption of other substances [6].

Thus, this type of consumption reinforces the positive expectations of the effect of alcohol preventing the anticipation of risks or damages caused by the substance. Often, BD is not perceived as a health problem but as a socialization behavior, which may contribute to the maintenance of this type of consumption and the possibility of assuming the dependency pattern. The practice of BD integrated into the socialization behaviors of youngster's points to a consumption of alcoholic beverages with the aim of the intoxication, since the appreciation of the hedonic properties of alcoholic beverages does not seem to integrate the consumption habits of this population [7].

This type of consumption may interfere with the development of relational and personal skills inherent to the stage of development in which young people live. Thus, it will be expected that, despite the increase in chronological age, the behavior presented may be the characteristic of a developmental stage that does not correspond to its age group [8].

Educate young people to the consequences of this type of consumption assumes an important strategy in the promotion of healthy behaviors, since it can prevent the occurrence of socially maladapted behaviors and the evolution to a pattern of dependency. The integration of social skills training programs, coping strategies and self-control strategies are important measures to be included in programs to prevent alcohol consumption and particularly BD. 


\section{References}

1. World Health Organization (2018) Global status report on alcohol and health. WHO Press, Switzerland.

2. Arnett J (2000) Emerging Adulthood a theory of development from the late teens through the twenties. American Psychologist 55(5): 469-480.

3. Adan A, Forero DA, Navarro JF (2017) Personality Traits Related to Binge Drinking: A Systematic Review. Frontiers in psychiatry 8: 134

4. Timko C, Sutkowi A, Pavao J, Kimerling R (2008) Women's childhood and adult adverse experiences, mental health, and binge drinking: the California Women's Health Survey. Substance abuse treatment, prevention, and policy 3:15.
5. Chen Y, Feeley TH (2015) Predicting Binge Drinking in College Students: Rational Beliefs, Stress, or Loneliness? Journal of Drug Education 45(34): 133-155.

6. Brown JL, Gause NK, Northern N (2016) The Association between Alcohol and Sexual Risk Behaviors among College Students: A Review. Current addiction reports 3(4): 349-355.

7. Erikson E (edition) (1963) Youth: Change and challenge. New York Basic books.

8. Sussman S (2013) A Lifespan Developmental-Stage Approach to Tobacco and Other Drug Abuse Prevention. ISRN Addiction Article ID 745783: 1-20. 